\title{
LA FÁBULA DE CHILE. LA TRANSITOLOGÍA COMO RAISON D`ETAT
}

\author{
The Chilean Fable. \\ The Transitology as a raison d etat \\ Rodrigo Karmy Bolton ${ }^{1}$ \\ rkarmy@gmail.com
}

\section{Resumen}

La hipótesis del presente ensayo plantea que la transición no fue simplemente un período en la historia, sino ante todo una raison d etat construida a partir de la estructura narrativa de la fábula. Como tal, plantea un relato que lleva como presupuesto el "había una vez" sobre el cual se desprende una moraleja que guía el modo de ejercer el gobierno vía las formas del goverment by consent. Si la fábula es un discurso moral construido en base a la escena de dos animales que cometen un error y dejan una moraleja, el discurso transicional fue una fábula que apeló al "había una vez" (Allende y la experiencia de la Unidad Popular) desde cuyo error se concluye una moraleja: gobernar "en la medida de lo posible".

Palabras clave: fábula, transición, raison d’etat, Allende, neoliberalismo.

\begin{abstract}
The hipothesis of this essay proposes that the transition was no a simple period of political history, but a raison detat built from the narrative structure of the fable. That's why it places a story that holds the "once upon a time" as its premise that make possible to conclude a moral lesson that guides the mode of how to govern through the technologiés of the goverment by consent. If the fable is a moral discourse built from the scene of two animals that make a mistake and leave a moral lesson, the transitional discourse was a fable that appeal to the "once upon a time" (Allende and the Unidad Popular experience) as an error that concludes a moral lesson: govern "as far as possible".
\end{abstract}

Keywords: fable, transition, raison d'etat, Allende, neoliberalism.

Fecha de Recepción: 10/04/2018 - Fecha de Aceptación: 15/06/2018.

\footnotetext{
${ }^{1}$ Doctor en Filosofía -mención Filosofía Moral y Política- por la Universidad de Chile, Chile. Profesor e Investigador del Centro de Estudios Árabes de la Facultad de Filosofía y Humanidades de la Universidad de Chile y profesor de la cátedra "Mundo árabe contemporáneo" en la carrera de Relaciones Internacionales de la Universidad de Santiago de Chile y del Seminario de Filosofía en el Departamento de Filosofía de la Universidad Metropolitana de Ciencias de la Educación, Chile.
} 
"(...) la razón del rey es que sea uno que presida y que sea un pastor que busca el bien común de la multitud y no el suyo."

Tomás de Aquino.

"Bebo por la casa saqueada por mi vida perdida por ti y por la soledad entre los dos. bebo por la perfidia de los labios por el frío espectral de los ojos por este mundo cruento y burdo y porque ningún dios nos podrá ya salvar." Anna Ajmátova.

\section{Fábula.}

El discurso transitológico implementado en Chile después de la dictadura de Pinochet fue estructurado en base a la narrativa de la fábula. Como tal, consideró a la historia como aquella instancia que ofrecía lecciones, instruía a los hombres y les moralizaba respecto de lo que se podía y no podía hacer. Ir más allá de los "límites" podía traer enormes consecuencias. Transgredir el pacto transicional podía implicar volver al había una vez que operaba como presupuesto legitimante de toda fábula: si la izquierda pretende gobernar, no deberá jamás repetir la experiencia de la Unidad Popular porque si lo hace, vendrán nuevamente los militares a "poner orden".

El mensaje de la fábula es claro: "había una vez una Unidad Popular que transgredió el pacto oligárquico y, entonces, tuvo que venir el golpe de Estado". Culpa de los demócratas antes que de la oligarquía militar-financiera, culpa de quienes imaginaron otra vida posible antes que aquellos que se opusieron a él. Moraleja: "no repita la experiencia de la Unidad Popular, porque sino, vendrá el lobo feroz".

Impugnar a los empresarios y a los militares, tal como habría ocurrido en la Unidad Popular, implicaría un "retroceso" al avance democrático. Subrayo a la Unidad popular porque es fundamentalmente contra ella -en la medida que habría sido el origen de la dictadura- que se dirige el relato de la fábula sobre el cual se erigió el discurso de la "transición". Contra su conjura la fábula de Chile configura la narrativa de la democracia. La "lección moral" legada por el discurso de Allende en La Moneda dirigido al pueblo para defender la República, fue invertida en la lectura de los "transitólogos" que leyeron en ella una "moraleja" antes que un gesto de resistencia. Porque el sintagma "lección moral" no designa en Allende una lección que deban aprender los demócratas, sino un gesto ético-político 
dirigido contra los golpistas: estos últimos fueron quienes traicionaron el fragor de la República, la voz que, en medio del hundimiento fáctico, reivindicaba una nueva forma de vida que rompía con el pacto oligárquico de Chile. La "lección moral" de Allende, quizás, tuvo la intensidad de una parrhesía cuyo "coraje por la verdad" podía abrir las condiciones para una vida diferente a la que había impuesto el pacto oligárquico (Foucault 1984).

Sin embargo, los "transitólogos" invirtieron el sintagma originalmente apuntado por Allende contra los golpistas, para dirigirlo contra Allende y la experiencia de la Unidad Popular. En el fondo, tal inversión, implicó la producción de una culpa dirigida a sancionar al pueblo de su gesta. Con ello, el coraje de la verdad característico de la Unidad Popular se convirtió en un dispositivo de confesión de la nueva matriz pastoral y así, la culpa como forma de captura de los cuerpos, podía dirigirse contra aquellos que pretenden impugnar el nuevo pacto oligárquico establecido por la dictadura cívico-militar. El síntoma de dicha inversión reside en que los demócratas de hoy fueron precisamente los golpistas de ayer (la Democracia Cristiana) y a la inversa: los demócratas de ayer serán quienes profundicen el orden de los golpistas de hoy (el socialismo renovado). Todo se articulaba en base al clivaje proveído por la producción de una culpa dirigida al pueblo cuyo efecto político consistirá en la capacidad para capturar a los cuerpos, poner a la vida contra la vida, y ensamblar así la transitología en base a la narrativa de la fábula como una nueva y eficaz raison d'estat.

La caída del muro de Berlín catalizó las cosas, puesto que la historia mundial prescindía enteramente de la referencia de la ex-URSS, pero también hizo lo suyo el euro-comunismo, que desde finales de los años 70 terminó por "renovar" al socialismo convirtiéndolo en el mejor aliado del nuevo patrón de acumulación neoliberal. La izquierda asumió el discurso de los vencedores "renovándose" y transformando así, al otrora conflicto de clases sostenido por la tradición marxista, en una querella remitida a la nueva episteme proveída por la sociología de la comunicación.

En este escenario, la raison d etat, se configura bajo la estructura de la fábula: había una vez -la Unidad Popular- que terminó causando el golpe de Estado de 1973. Moraleja: no vuelvan a la dinámica conflictiva -es decir "política"- de la Unidad Popular e implementen el goverment by consent promovidos por los saberes de la comunicación y el discurso de la "reconcilación": “(...) el reemplazo de la política como confrontación, dice Tomás Moulián (1998), por la política como administración, generará las condiciones de la perfecta gobernabilidad". Para no repetir la "transgresión" cometida por la Unidad Popular será preciso sustituir a la "política como confrontación" por la "política como administración", al discurso de la "lucha de clases" por el de la "razón comunicativa" o, si se quiere, al modelo legado por la parrhesía, como el discurso que denuncia la verdad en un conflicto inmanente a la 
pólis, por el de confesión, como dispositivo de neutralización de todo conflicto a favor de la conducción pastoral.

Pero no sólo de neutralización vive la nueva realidad neoliberal: ante todo, de la completa "economización" de la vida social al punto de sustituir el tradicional homo politicus por el homo economicus de la nueva antropología neoliberal (Brown 2017). Clave a este respecto es atender a que, mucho más allá de las críticas schmittianas al liberalismo, según las cuales, éste produce efectos de despolitización, la razón neoliberal produce una "economización" en la que transforma enteramente el código mismo de la política. No es simple despolitización como reconfiguración total de la política bajo el modelo de la economía corporativa-financiera. El proceso de "economización" implicó la articulación del ensamble de una fábula: para no volver al había una vez del reino animal en el que se jugaba la confrontación, era necesario ordenar todas las piezas del nuevo orden bajo una sola premisa: la "moraleja" de la fábula que ofrece las lecciones necesarias para "no repetir" la debacle de la Unidad Popular en favor de una completa "reconciliación" que significó dejar intacta -y desarrollar sus posibilidades hasta su extremo- la institucionalidad impuesta por Pinochet y su comparsa de intelectuales neoliberales.

\section{Conversión.}

Como raison d'etat la "transitología" se convierte en la fábula de Chile. Construida durante la dictadura por parte de intelectuales en el exilio que comenzaron a abrazar la "renovación socialista", la "transitología" asumió la narrativa de una fábula en la que el soberano (los vencedores de 1989) intenta expurgar su violento residuo de la bestia (la Unidad Popular y la consecuente dictadura) que le había dado lugar. Lejos de todo "tránsito histórico" (Allende), el soberano contempla la historia hacia atrás, desde su fin. Como el "sabio" del "fin de la historia" que una vez, Alexandre Kojéve (2014) leyó en la filosofía de Hegel, el soberano tuvo lugar gracias a que hizo saber que sabía hacer, articulando a la fábula de Chile como una novedosa y eficaz técnica gubernamental. El soberano podía dar lecciones morales, sería el "sujeto-supuesto-saber", capaz de instruir a su pueblo las "moralejas" aprendidas de un pasado bestial (el había una vez).

Sin embargo, el acto inaugural de la fábula no fue el plebiscito que dio triunfo al "No". Fue la performance confesional de Patricio Aylwin al recibir el Informe Rettig en la que pidió perdón a los chilenos en nombre del Estado de Chile. En dicho acto, se daba vuelta la página. Los conspiradores de ayer (Aylwin mismo uno de ellos) recibían la contrición moral necesaria para conjurar al había una vez expresado en el Informe y, en nombre del Estado, "pedían perdón" a los chilenos. 
Un acto de confesión público, en el que, por intermedio de Aylwin, el Estado de Chile reconocía su culpa y, con ello, la expiaba frente al tribunal divino de todos los chilenos. El dispositivo de la confesión operó, su drama y contrición también. Hay llantos y, por tanto, "lecciones" que aprender, moralejas que enseñar. Aylwin fue aquél que cargó con el pecado de la bestia y lo confesó en el escenario estatal convirtiéndose así, en legítimo soberano.

Se trataba de una "conversión" (metanoia) -como decían los antiguos cristianos- de la transformación de un pecador en un salvo, de una bestia en un soberano -y no más "tirano"-. (Derrida 2010) Carga la "cruz" y se purifica con su luz: Aylwin convirtió al Estado de Chile e hizo de la mentada "transición" su interminable procesión. El Estado es declarado culpable iniciando así su "tránsito" hacia su redención (la "plena democracia").

El Informe Rettig opera como confesor cuyo grosor documental exhibe al Estado en su dimensión bestial, Aylwin como el dispositivo performático de su "conversión" en soberano. El Estado dejaba el "paganismo" que lo había hecho presto a la tiranía, para "evangelizarse" y volverse enteramente hacia la democracia que no fue otra cosa que un kerigma: el anuncio de la "buena nueva" que Cristo ha llegado y que, por tanto, la "alegría" no hará más que venir. No es casualidad que la campaña del No haya llevado la idea de "alegría" y que, posteriormente, al ser presidente, Aylwin se haya caracterizado por su sonrisa permanente como su signo político característico. Militares y civiles, empresarios y trabajadores podrán convivir sólo si dejaban atrás la lógica de la "confrontación" y daban curso a la gloriosa fórmula de la "comunicación". Aylwin fue el rostro de la fábula, la voz que moralizó a la historia, el presidente que gestó la liturgia para confesar los pecados y purificar el alma del Estado.

"Pido perdón" fue la fórmula de la liturgia en la que la dinámica tiránica del Estado podía dar paso a la nueva escena democrática. Justamente el propio Aylwin que había apoyado el golpe de Estado de 1973 se convierte ahora en el sumo sacerdote de la nueva liturgia democrática. Aylwin fue el pastor de la transición. Su sacerdote con plenos poderes, aquél que anunció el kerigma "alegremente" y que, a través de la confesión, pretendía conducir a su pueblo hacia la salvación. Precisamente fue un "demócrata cristiano" quien debía conducir hacia un Estado "puro" sin "mancha" alguna de su pasado tortuoso, un Estado que podía traducirse en la transparencia de la nueva democracia en que ya sin mancha ni pecado, podía implementar "mesas de diálogo" y reconciliar a todos los chilenos gracias al dispositivo "glorioso" de la comunicación.

La trama pastoral de la fábula de Chile funcionó en base a dos mecanismos muy precisos: la glorificación por la que se sustituyó la política de la confrontación por la política consensual de la comunicación y la culpabilización (tramitado moralmente y luego convertido en dispositivo económico) en la que se prodigó de 
una culpa histórica que posibilitó la renovación neoliberal de las izquierdas y la aceptación incondicional del esquema transicional bajo amenaza del retorno "mítico" del había una vez. Glorificación y culpabilización constituirán el reverso especular el uno del otro pues ambas implicarán el desplazamiento de la lógica sacrificial desde el ámbito político-militar hacia el campo corporativo-financiero que posibilita la "economización" de todos los ámbitos de la vida social. Con ello, la fábula de Chile se convirtió en el pivote discursivo del neoliberalismo con el cual se recodificó enteramente la política chilena que, como tal, tuvo tres efectos decisivos:

1.- La final convergencia entre dos coaliciones politicas en una misma concepción "pastoral" que terminó por constituir a un solo Partido Neoliberal. No existe un "duopolio" sino un verdadero "monopolio" político-electoral que, aceitada por la institucionalidad autoritaria legalizada en la Consttución de 1980, conserva tres tendencias diferentes: una derecha, un centro y una izquierda. No obstante sus diferencias internas, pervive un consenso fundamental que consiste en la idea de que el neoliberalismo es el único horizonte político posible, la única fórmula para la vida común, el dispositivo exclusivo de toda racionalidad política. No hay "duopolio" sino un solo Partido Neoliberal que, con sus diferencias internas, no ha dejado de renovar el pacto oligárquico que transó con la dictadura. El Partido Neoliberal tiene diferencias internas, pero entre ellas el neoliberalismo se convirtió en el único horizonte de inteligibilidad. Como todo partido, el Partido Neoliberal lleva consigo un discurso que fue capaz de recodificar la política transformando enteramente el léxico utilizado: bonos, subsidios, economía, índices, empleo, proyecto y otros tantos términos, comenzaron a poblar la totalidad del nuevo vocabulario político, al punto de recodificar enteramente la política contemporánea en base a su "economización".

2.- La culpabilización-economización-extrema de la vida social. Denominaremos "culpabilización" al proceso de captura de los cuerpos en el que quedan a disposición de un poder. Atendiendo a la noción de "violencia mítica" desarrollada por Walter Benjamin en Para una crítica de la violencia (2017) según la cual, la culpa es la marca de una violencia fundadora y conservadora del derecho (violencia "mítica"), diremos que la "culpabilización" designa un proceso de subjetivación en el que el "mito" del había una vez que estructura a la fábula de Chile, se reproduce infinitamente en cada individuo bajo la forma de la economía. Pero, si tal violencia marcó a los cuerpos con el sello de la represión durante la dictadura, ahora lo hace bajo el modo del goce. Antes eran los campos de concentración, ahora son los reality shows, antes se imponía un catolicismo represor, ahora asume la forma de un neoliberalismo consumidor. Pinochet sigue operando pero en "espíritu". No con la violencia militar, sino con la violencia del capital. Subrayando la duplicidad semántica del término alemán schuld que 
designa, a la vez, "culpa" y "deuda", diremos que la culpa política atribuida al "cáncer marxista" de la dictadura se trueca en la "deuda" económica de la democracia. Pinochet marca una filiación empresarial-militar que finalmente termina sustituyendo el orden dictatorial de corte cívico-militar por el nuevo orden consensual de carácter cívico-empresarial.

La culpabilización vació la "alegría" -la insurrección de la felicidad pública abierta por la Unidad Popular- que había sido la pasión central de la potencia popular, convirtiéndola en un simple slogan publicitario, deviniendo así una nueva era de "tristeza". Así como la felicidad pública de los años previos al plebiscito asumía una noción efectiva de la democracia, la tristeza que sobrevino implicó su articulación puramente formal que devino en su destrucción: los grandes intereses corporativo-financieros dominaron sobre la democracia $y$, a su vez, dicha democracia favoreció su dominio vaciándose enteramente de sí misma. Tal proceso se articuló a partir de la fábula de Chile toda vez que el miedo de "volver" al había una vez operaba como la violencia mítica que jamás pudo conjurarse y que, mas bien, aceitó las condiciones para la consolidación de las nuevas formas de terrorismo corporativo-financiero. El miedo al había una vez y la supuestas "lecciones morales" legadas por la experiencia de la Unidad Popular reinterpretada por los "vencidos" que creyeron ser "vencedores", fue el motor de todo el sistema que utilizó el doblez glorificación-culpabilización para proveer de alabanzas de ser un país "ejemplo" de América Latina y, a la vez, individualizar la culpa sosteniendo que el sistema era perfecto, pero que los individuos son los responsables: las palabras de José Piñera fueron elocuentes al respecto. En una entrevista realizada en TVN durante el año 2017 respecto del sistema de las AFP y su lógica de capitalización individual que él mismo había creado en los años 80, respondió que era un "Mercedes Benz" que requería "bencina” metaforizando con ello el hecho de que si los individuos no tienen una jubilación digna será exclusivamente porque ellos no cotizaron como correspondía, no le proveyeron al "Mercedes Benz" la cuota de combustible que requería.

El núcleo "mítico" de la fábula de Chile experimentó una "democratización": los detenidos desaparecidos fueron "culpables" de su propia desaparición; las mujeres terminaron siendo culpables de ser golpeadas, los viejos culpables de no haber cotizado, los estudiantes de estar endeudados, los enfermos culpables de haberse enfermado. Porque finalmente ¿qué es la "culpa" (o "deuda") sino una de las formas más originarias con las que el poder captura a los cuerpos y la eficaz tecnología de obediencia? Y, por su parte, ¿qué fue lo que la potencia popular impugnó en las revueltas del 2011 cuando dirigió sus fuerzas contra el Crédito con Aval del Estado sino tal forma de captura característica del capital financiero?

3.- La división "gnóstica" entre lo social y lo político. Como los antiguos "gnósticos" pretendían dividir el alma del cuerpo, así también, el discurso 
neoliberal divide a los social de lo político. Como todo "gnosticismo", el neoliberalismo considera a la "política" la fuente del "mal" y a la "economía" el exclusivo lugar del "bien". El neoliberalismo es un gnosticismo cristiano en el que la esfera social aparece como un ámbito a-político manejado exclusivamente por el discurso "experto" y la esfera política como aquella que debe quedar supeditada a la primera puesto que, como un "mal necesario", debe ejercer un gobierno tal que permita generar las condiciones para la buena circulación de la economía. Nada debe interferir su labor puramente técnico-procedimental, ninguna fuerza puede desviar su función exclusivamente económica. Así, lo "social" queda reducido a un conjunto de funciones económicas y lo "político" a una simple administración que debe velar para el desempeño de lo "social". La circularidad de la máquina es perfecta en este sentido. Pero, dado que el dispositivo neoliberal divide la vida entre lo social y lo político, necesariamente debe apropiarse del Estado para remodelar su función subsumiéndolo a un rol corporativo-financiero (es lo que, en sus lecciones, Foucault (2010) llamó "régimen de veridicción").

En el léxico de Hayek la división entre lo social y lo político se traduce en la diferencia entre la "libertad" y la "razon": esta última debe generar las condiciones económicas para el surgimiento de la primera. La "razón" es limitada, pero no está ausente tal como lo concibió la mística nacionalsocialista, ni tampoco excesiva como lo planteó el totalitarismo soviético. El neokantismo hayekiano introduce la idea de que la "razón" debe generar las condiciones económicas de la libertad o, lo que es igual, que el Estado debe proveer las condiciones institucionales para el libre curso del mercado. Pero generar las condiciones no significa jamás "regularla" sino "producirla". Por eso, la "libertad" no es mas que un efecto técnico del Estado y no un dato "natural" como lo concebía el liberalismo del siglo XVIII.

En este sentido, el neoliberalismo es otra forma de estatismo. Pero, más aún: que el neoliberalismo sea un gnosticismo cristiano significa que concibe la relación Estado-mercado (o razón-libertad) en analogía con la relación metafísica almacuerpo. Y todo su proyecto consiste en desprender al mercado del Estado o, lo que es igual, en implementar su proyecto escatológico de "salvar" el alma del cuerpo. Por eso, para Hayek, el neoliberalismo no fue jamás una simple teoría económica, sino una verdadera "filosofía de la libertad". Y, quizás, por ese mismo motivo, fue la dictadura de Pinochet la que aceitó las condiciones para su completa implementación: sólo una dictadura que se había propuesto "extirpar el cáncer marxista" podía converger con el proyecto escatológico del neoliberalismo orientado a la salvación del alma.

Tanto la dictadura como la democracia se articularon escatológicamente cuya bisagra central fue el discurso neoliberal como la metafísica de la pequeña burguesía planetaria, último reducto en el que una noción espiritualista de corte 
"aristocrática" podía sobrevivir a la irrupción del marxismo. En cuanto gnosticismo cristiano el neoliberalismo sostiene su poder en la división entre lo social y lo político ofreciendo, sin embargo, la pauta de lo que podría significar la insurrección: habrá impugnación de su mecanismo sólo en la medida que la potencia popular se mantenga irreductible a dicha división promoviendo prácticas capaces de politizar al plano social y socializar a la institucionalidad política (Karmy 2017). La capacidad para desactivar la división entre lo social y lo político constituye la premisa fundamental para ir más allá del horizonte neoliberal.

\section{La escena.}

La escena es simple. Despierta a míticos personajes que inundan la imaginación. Abraza una serie de intensidades con las que se resuelve una precisa teofanía en la que se desencadenan las más altas utopías y las más terribles pesadillas. La oikonomia pastoral de la fábula de Chile brinda una escena con sus personajes y su trama. Hay una repetición que no deja de suceder. Como una familia que, una y otra vez, pretende enterrar a sus muertos sin tener a sus muertos, dar verdad sin decir la verdad y distribuir justicia sin justicia y que, por eso, no puede dar vuelta la página, no puede inaugurar nada nuevo, no puede abrir una nueva época histórica. La fábula gestiona el mito y lo pone a jugar en una tríada imaginaria constituida por el pastor, la oveja y el lobo feroz.

Orientada a la salvación de las almas de todos y de cada uno, la oikonomía pastoral de la fábula se configuró en una tecnología del poder de corte económico. Cada oveja está en situación de pecado, cada pastor se ocupa de cada una de ellas para conducirla a su salvación. La matriz pastoral arraiga en una tríada perfecta: el pastor, la oveja y el lobo feroz: el pastor protege a las ovejas de la amenaza del lobo. Las conduce a un lugar seguro, les conmina a estar unidas y establece una vigilia permanentemente sobre ellas. El pastor se ocupa de cada una de las ovejas y se presenta como un poder benévolo que sabe qué es lo que les hace bien a ellas porque hace del lobo su presupuesto fatal.

Aylwin reeditó la metáfora del pastor en la escena misma del poder. De ahí que el despliegue neoliberal consumaba la oikonomía pastoral por excelencia. El pastorado chileno se contó una fábula: había una vez unas ovejas que quedaron descarriadas gracias al mal pastor que fue Salvador Allende. Se pelearon entre sí e hicieron que viniera el lobo feroz. Moraleja: si las ovejas quedan sin pastor, el lobo feroz puede venir de nuevo a devorarlas. Una fábula tan simple que ha sido contada mil veces. Una fábula que tejió el dispositivo gubernamental del Chile contemporáneo y que, después del Golpe de Estado de 1973 fue contada en una simple fórmula: si la oveja desobedece al pastor puede venir el lobo. Historia cuya simpleza y sencillez la convirtió un ensamble preciso de la nueva raison d’etat. 
La fábula de Chile es sobre todo el dispositivo mítico orientado a consolidar la obediencia en la época de la renovación del pacto oligárquico como reprogramación neoliberal. Nueva raison d’etat que subjetiva a la potencia popular como rebaño para prevenir la llegada del lobo y conservar así la prevalencia de los poderes fácticos. Como gestión del mito, la fábula despliega una violencia conservadora que perpetúa el pulso de la violencia fundadora en el seno de lo fundado. La fábula fue tal dispositivo, orientado a la conservación del orden civil para impedir que el hombre se volviera el lobo del hombre.

La performance aylwiniana implicó la conversión del Estado: de un Estado tiránico (bestia) a un Estado democrático (soberano). Con ello, se restituyó la figura del pastor cuya característica central se define por ser quien sabe conducir a sus ovejas. Si la oikonomía pastoral implicó la institucionalización de la trama loboveja, la potencia de clase, expresada en los movimientos sociales, irrumpieron con su destitución. El pastor sabe ahuyentar a los lobos del rebaño, educando a las ovejas para no caer en sus argucias, pero no sabe que hacer con un pingüino. Como un animal que niega a su propia especie, que excede los límites clasificatorios, el pingüino acontece como un devenir menor que cruza la escena pastoral volviéndola inoperante. El kerigma pastoral que anunciaba la "buena nueva" de la democracia cae y se muestra vacío. No es un lobo, es un ave que no vuela, es un "pájaro-niño" que cruza la tormenta. Un pingüino en un establo resulta improcedente, un pastor en el mar también. El elemento pingüino yace en el interticio de la tierra y el mar; el elemento pastoral es la tierra; como un ave que no vuela o un hombre que no habla, el pingüino es la infancia de Chile.

El pastor nada sabe de pingüinos, su fábula ha sido tramada en la matriz loboveja: ¿el pingüino es una oveja o un lobo, es el bien o es el mal? Pregunta última en la que el pingüino no cabe. Ni oveja ni lobo, ni bueno ni malo, el pingüino es el inmoralismo de una infancia. Frente al pingüino, el pastor queda fuera de juego y la fábula ya no puede funcionar. El pastor ya no puede "explicar", ni el pingüino -en cuanto no es oveja- está obligado a obedecer. Estalla el "comunismo de las inteligencias" que revoca al "sujeto-supuesto-saber" impuesto por la tecnología pastoral (Rancière 2014). Hace caer su encanto, su investidura litúrgica y muestra que tras sus enunciados no hay más que nadie.

\section{Secularización.}

La fábula ha podido gestionar el mito del había una vez cada vez que se han impugnado sus premisas, fantasmas y efectos. El núcleo de la fábula ha podido ser la culpabilización mítica de una violencia operada militarmente y profundizada económicamente. Cada vez que su orden se ve amenazado, funciona como una suerte de "carta bajo la manga" que posibilitó la exclusión de una tercera voz en el 
espectro electoral. Por mucho tiempo expresado en la marginalidad del Partido Comunista de Chile liderado por Gladys Marin, el "tercero excluido" del sistema electoral no podía ingresar sino bajo acusación de que su presencia amenazaba con hacer volver el había una vez: que ganara la derecha y que, por tanto, volviera "Pinochet". Como si Pinochet sólo se pudiera reducir exclusivamente a la "derecha política" y no en la coalición que gestionó entusiastamente su legado.

Se trata del espectro del lobo feroz que amenaza con volver para arruinar el frágil equilibrio instituido por la transición. Espectros de la democracia de una democracia espectral cuyo terror se cristalizó en los militares que amenazaban con volver y en los empresarios que amenazaban con huir: la fábula, supuso siempre la existencia de un lobo feroz a cuyo espectro el pastor debía conjurar permanentemente: que no hubiera justicia contra los militares sino "en la medida de lo posible" y que se profundizara el sistema económico neoliberal garantizando el "crecimiento"; fueron los efectos políticos del dispositivo mítico en el que el lobo feroz operaba como el pivote de la fábula.

La premisa de la fábula fue ésta: no había más posibilidades que una democracia "en la medida de lo posible". Mas tal fórmula puede traducirse así: democracia en la medida de los militares o, si se quiere, orden civil a la medida del capital corporativofinanciero. "Medida" es el muro, el límite irrebasable que contiene a la imaginación: la dimensión de lo "posible" se halla determinada por la doble captura de la amenaza del lobo feroz y por la vigilia del pastor. La multitud sólo podía circular como oveja entre los límites del pastor y del lobo como dos polos antitéticos de una misma máquina que las glorificaba y culpabilizaba funcionando como dos rostros de un mismo funcionamiento en el que el lobo se hacía indistinguible del mismo pastor: en el año 2005 y desplazando la firma de Pinochet por su propia firma en la Constitución de 1980, el presidente "socialista" Ricardo Lagos, intrduce una nueva captura de la potencia popular al interior del marco dictatorial.

Es aquí donde se cumple lo que Armando Uribe Arce -autodeclarado "pinochetólogo" - ha llamado el fantasme que, cristalizado en la figura de Pinochet no dice más que un solo mensaje: “(...) la violencia que quiere ser legítima. La violencia que busca o trata de legitimarse -sigue Uribe- La violencia que se considera a sí misma legítima" (2001 49). Pinochet es la firma de una violencia cuyo "hacerse legítima" se realiza en Lagos. Mas bien, diremos, que tal firma no podía sino realizarse en Lagos, puesto que jamás existe una violencia fundacional en sí misma si no se acompaña de su despliegue legitimante. Cuando Pinochet da el golpe de Estado de 1973 éste fue articulándose como "golpe" con el despliegue de los diversos dispositivos que terminan por refundar al Estado de Chile configurando una nueva "razón" cuya culminación tiene lugar en 1980 cuando se aprueba la Constitución y, retroactivamente, se le da una legitimidad civil a la dictadura. 
En otros términos, no es que los demócratas hayan "traicionado" a la democracia - una tesis demasiado apegada a un "ideal", precisamente- sino que ha sido en y como democracia el modo en que se cristalizó la dictadura, en virtud de la violencia de la firma y la firma de su misma violencia. Entre Pinochet y Lagos no hay más que la consumación del fantasme entrevisto por Uribe que anuda al Reyno de Chile, el "peso de la noche" en el que habría que preguntar ¿por qué esa violencia "querría" ser legítima, por qué un Pinochet "querría" volverse Lagos? Teleología que articula una filosofía de la historia y que se presenta como violencia fundacional necesariamente a posteriori cuando todo el aparato administrativo termina por constituirla. A esta luz, el verdadero "poder constituyente" no está jamás al principio, sino siempre al final, una vez que Lagos reconoce la firma de Pinochet y la desplaza en y como democracia.

Será precisamente en la complejidad de este nudo donde lobo y pastor se tornan indistinguibles; tal indistinción redunda en la distinción temporal inscrita por la fábula: antes era el lobo hoy es el pastor. Mas, precisamente porque sabemos del lobo après coup, la fábula es sólo la ficción -la narrativa-desenvuelta en una teleología (la historia tiene principio y final), mas constituye la maquinaria de un poder en el que lobo y pastor se anudan mezclándose, exhibiéndose como el reverso especular el uno del otro, en una misma lógica. Ambos son una sola modalidad de producción del terror que mantiene viva la ficción del poder y el poder de la ficción y que encontrará en la firma de Lagos la imagen que condensa toda la racionalidad de la "transición".

Esa firma, que articula el entramado pastoral del loboveja sobre el cual se fundó la fábula de Chile se puede formular parafraseando a Schmitt: todos los conceptos concertacionistas fueron conceptos pincohetistas secularizados. La democracia se vuelve una "secularización" de la dictadura y, con ello, el lugar que cristaliza su violencia, ahora, en y como escena neoliberal. He aquí, el espectro de su violencia, la complicidad de un orden (económico y político) antes que la diferencia, la discontinuidad con la "larga tradición democrática" de un país cuya sujeción militar-empresarial ha sido permanente. La transitología fue la fábula de Chile que se articuló como raison d`etat. Un operador agotado en sus posibilidades, pero absolutamente vigente en su facticidad. ${ }^{2}$

2. Menester es recordar que el término "secularización" ha de entenderse sinónimo de "economización" en el sentido que inmanentiza los términos inscribiéndolos en una singular filosofía de la historia que comienza con la trascendencia y termina en la inmanencia del cuerpo de Cristo. Por eso, la instalación de la razón neoliberal es un proceso de secularización no porque deje de lado la dimensión sagrada y sacrificial de la existencia (más bien la profundiza en la forma del "capital humano") sino porque es capaz de "economizar" todas las relaciones sociales o, lo que es igual, "inmanentizar" el poder del capital en la cotidianeidad de la vida social. 


\section{Pino-let.}

En esta escena ¿cómo leer el nombre Bachelet sino como una homofonía que desplaza, retarda y sublima el arcano Pinochet? Bachelet-Pinochet configura una trama mítica en la que la soberanía (Bachelet) se revela como la bestia (Pinochet). Trama que articula a la raison d’etat en el doble rostro soberano-económico de una misma maquinaria política: ¿qué de Pinochet repite en Bachelet? pero a su vez: ¿qué de Bachelet distancia a Pinochet? El "pino" lleva una homofonía con el "pene", por eso, Pinochet fue siempre Penechet cuyo falocentrismo mantuvo una soberanía intacta. Desde Pinochet a Lagos y desde éste a Piñera (Piñera justamente restituye el pi-ne de pi-no de Pinochet): el cambio entre un pino y un bache ha constituido el efecto más decisivo de la destitución estudiantil. Estos han horadado la fábula trastocándola al punto de obligarla a recurrir a otras formas, sustituyendo a un pino-pene (Pinochet) por un bache (Bachelet).

El bache del pene -que porta su reverso especular: el pene en el bache mostrando la violación del cuerpo femenino ensombrecido bajo el edificio de la fábula. El bache del pene podría haber sido catastrófico para la fábula, pero el sufijo let garantiza homofónica y míticamente la presencia espectral de Pinochet. Es ahí donde tiene lugar la violación femenina. Bachelet, apellido de un general de la FACH duplicado en la figura de una madre que dio cuenta del bache (Fach-Bach) de la fábula para potenciarlo bajo nuevos registros. A esta luz, bache hace homofonía con fach y facho, dándonos algo así como Fache-let y reconstituyendo así, en el significante de la democracia presente en el nombre de la Presidenta, el oscuro peso del significante de la dictadura.

\section{Nadie.}

El efecto inmediato del alzamiento de la potencia popular ha sido sacar a la luz la dimensión licantrópica del pastor. Es decir, que entre pastor y lobo, entre Lagos y Pinochet no había más que un reverso especular en el que ambos se tocaban, se gozaban, pues, en virtud del segundo tiempo del trauma, no podían sino articularse en una misma unidad. Su potencia ha tomado las calles, exhibiendo al trono completamente vacío, exento del "sujeto-supuesto-saber" que se acomodaba en él. El simulacro del saber hacer implementado por la fábula transitológica, fue destituido y, exactamente ahí, esa "clase política" ya no sabe que hacer. Sin embargo, lo que se descompone es la arquitectura de un orden sostenido enteramente en base a la fábula. Lo que ha estado en juego en el Chile contemporáneo no es simplemente una "falta de confianza" a la clase política -como repite el cliché periodístico- sino la destitución de la fábula como raison d’etat. 
Uno de los momentos clave de tal destitución, se escenifica cuando Francisco Figueroa, en ese entonces dirigente estudiantil, impugna a Sergio Bitar acerca del "Crédito con Aval del Estado". Como un profesor que pretende corregir al estudiante, Bitar exige a Figueroa que "escuche", que no se sienta que detenta la moral. Es ahí cuando estalla enfurecido: "Tengo mi vida entera dedicada a la política. Desde ministro de Allende, he estado exiliado, he estado preso, para que no venga un niño a descalificar de esta manera (...)". Bitar pretendió imponer la fábula, mostrando que él era quien verdaderamente sabía hacer, insistiendo en su trono, en la posición de aquél que sabe y, por tanto, debe gobernar. Figueroa lo cuestiona, le cambia los supuestos desde el cual Bitar y los transitólogos articularon su raison d’etat, planteando que no se trata de cómo se mejora un sistema que da prioridad a los bancos antes que a su pueblo, sino cómo se lo cambia enteramente.

Figueroa dirige sus dardos a la fábula que hace posible el funcionamiento bestialmente soberano de los bancos. El enfurecimiento de Bitar exhibe a la fábula en su facticidad, a los "demócratas" como los más fieles herederos de la dictadura. Aquellos que no sólo administraron su sistema, sino que también que profundizaron sus mecanismos. "Lucro" es la consigna que hunde a Bitar frente a Figueroa, "lucro" es la imagen que, condensando la catástrofe del Chile neoliberal, fue capaz de desactivar la fábula de Bitar. ${ }^{3}$

La revuelta estudiantil del año 2011 -eco de las diversas protestas acontecidas a escala global-fue la "alegre" despedida de 1989: si tomamos a 1989 no como una fecha historiográfica, sino como cifra paradigmática que trae a escena un triple proceso: el fin de los socialismos reales en Europa, la unilateralidad de los EEUU como potencia unívoca y del neoliberalismo como discurso único. Tal situación mantuvo dicha imagen hasta el 2011 cuando las revueltas árabes primero, y luego otras protestas se tomaron las calles del planeta. Es claro que todo

3. Una paradójica teoría de la potencia destituyente no sólo desplaza la configuración propiamente moderna del "poder constituyente" sino que inscribe a la relación de uso como una relación abiertamente política capaz de desactivar al conjunto de relaciones en las que ensamblan las "máquinas" del poder: "La proximidad entre la potencia destituyente y lo que, en el curso de la investigación, habíamos llamado con el término "inoperosidad" se muestra aquí con claridad. Entreambos está en cuestión la capacidad de desactivar o volver inoperante algo -un poder, una función, una operación humana- sin simplemente destruirlo, sino liberando la potencialidad que en ello permanece inactuada para permitir algo así como un uso diverso". Usar significará, entonces, desactivar los dispositivos que nos atraviesan, haciendo implosionar sus formas y ofreciendo una restitución de lo común. Como plantea Agamben, siguiendo en parte, la estela abierta por Foucault, se trata de "liberar la potencialidad" del "poder, función u operación" que la mantiene apresada. "Volver inoperante" significa abrir algo a sus múltiples usos o, lo que es igual, liberar el ser-de-potencia que lleva consigo. Porque lo que está presto al uso no es precisamente aquello que pueda ser "propio". Usamos lo que no es "propio" sino aquello que es "común", desactivando al dispositivo de la fábula, dejando sin efecto su funcionamiento (Agamben 2014 336-337). 
lo que ahí hay es un conjunto múltiple de procesos que cristalizan también en el proceso chileno ahí donde la lógica transicional era precisamente la foto que había congelado la política a 1989.

Sucedió que la palabra política -por mucho tiempo capturada por la política de los consensos- se democratiza y comienza a circular por las calles nuevamente, como había sucedido antes de 1989. Las consecuencias son prístinas: a pesar del monopolio mediático, los que "saben" de las moralejas de la historia dejan de tener su privilegio. Han sido removidos del trono que "supuestamente" les sostenía y hoy caen al abismo sin jamás haber aprendido a volar. La destitución del "sujeto supuesto saber" que había privado a los chilenos de la palabra política no fue otra cosa que su democratización que ofreció volcar a los chilenos a su capacidad de uso, al carácter común - inapropiable-de su potencia (Casanova 2016). Hoy, los chilenos han vuelto a experimentar su capacidad de uso en cuyo hábitat son: "(...) capaces de conductas imprevistas o de todos los vínculos posibles" como dirá Cavalletti (2013 52).

En la escena descrita entre Bitar y Figueroa, el ex-ministro se enfada y reclama la defensa de su posición histórica y moral frente al estudiante que le interpela. Defiende su lugar diciendo que ha sido ministro de Allende, y que además, fue preso y exiliado. No viene a la política como un aparecido, sino como alguien que hace saber que sabe hacer. Como alguien que puede dar "lecciones morales" y que, por tanto, pretende que Figueroa escuche y acate, que entienda que el CAE era lo que se necesitaba hacer en un momento determinado porque él sabía qué era lo que había que hacer.

En la perspectiva de su relato, no era posible expulsar a la banca y dar educación gratuita para todos, porque de hacerlo, se podía volver al había una vez que opera como el "presupuesto" que precisamente la voz de Figueroa venía a interrumpir. Ni espectralidad del había una vez, ni instrucción de una moraleja, la fábula de Chile queda rota, herida, maltrecha. Destituida de su verdad, ridiculizada de su lección, vaciado su lugar de enunciación: la potencia de clase expresada en los diversos movimientos sociales mostraron que tras sus "lecciones" no había nadie, ni nada. No había "sujeto-supuesto-saber" alguno, sino tan solo el bullicio de un simulacro, el (des) encanto de la fábula de Chile. Nadie estaba ahí para salvarnos, ningún pastor esperaba por nosotros. 


\section{Infans. ${ }^{4}$}

Se cuenta que, en una de sus tantas expediciones, fue Vasco Da Gama quien habría encontrado a unas extrañas aves que la historia terminará por llamar pingüinos. Aves con pequeñas alas, pero imposibilitados de volar, los pingüinos extendieron su fama en el imaginario europeo como los "pájaros-niños". El movimiento secundario en Chile fue bautizado bajo el nombre de pingüino. Como los demás, son pájaros, pero no vuelan, llevan consigo la marca de una infancia, el signo de una inmadurez.

El equivalente humano de las alas en los pájaros, es la palabra. Un humano que "no habla" fue calificado por la tradición latina como un infans. Grave problema de un humano que carezca de aquello que la propia tradición determinó como el elemento clave que define su naturaleza. Los seres vivientes que posean lógos (lenguaje, razón) serán calificados como humanos, aquellos que estén exentos de él, serán calificados de animales. Distinción política fundamental que cesura a unas vidas en un interior (los hablantes, por tanto, los "demócratas") y otras en un exterior (los no hablantes, los niños que deben ser gobernados).

Pero ¿qué puede ser un infans? El humano que aún no habla, que todavía no puede hablar, pero que está abierto al uso mismo de toda palabra. Infans designa la experiencia de nuestra capacidad de uso o no uso del lenguaje, el lugar en el que habitamos la potencia. No habitamos "en" potencia, sino "la" potencia como tal. Infans remite a una experiencia, antes que un estadio del desarrollo, al lugar de la potencia, más que un origen perdido en la vida del animal humano. In-fantia es el lugar de la diferencia entre viviente y humano, la potencia común que hace florecer las capacidades o fuerzas de uso (y de no uso) que una vez, la naciente tradición latina conjuró bajo la abyecta forma del "averroísmo" (Coccia 2005, Brenet 2015).

En Chile, quizás haya sido Guadalupe Santa Cruz quien haya descrito la experiencia in-fantil de la manera más radical, esto es, interrogando la oscura relación entre el viviente y lo humano para desactivar así el dispositivo comunicacional de la fábula transitológica: "Estuve largo tiempo salivando palabras en la boca. Estuve buscando sus formas, las busqué en un ángulo chueco que hay en el espacio, escribo porque no las encontré". (Santa Cruz 2011). Lejos de la inmediatez entre vida y lógos Santa Cruz nos ofrece la dificultad, el "ángulo chueco" en el que la

4. Con el término infancia no denomino simplemente a un estadio del desarrollo del viviente humano, sino a la incoincidencia entre vida y lenguaje, entre el viviente y el humano. Descubrimiento esencial de la tradición averroísta que, en nuestro tiempo, ha sido puesto en circulación por el trabajo de Giorgio Agamben y Jean François Lyotard: "Como infancia del hombre, la experiencia es la mera diferencia entre lo humano y lo lingüístico. Que el hombre no sea desde siempre hablante, que haya sido y sea todavía in-fante, eso es la experiencia" (Agamben 2003 70). 
antropología del "hombre" como animal racional naufraga sin retorno. Hay un retardo en el que se juega la eternidad de la palabra, un hiato que la hace buscar sus formas, en la que habita un "espacio" imposible de suturar.

El viviente no lleva consigo el lógos, por eso hay escritura: se escribe porque la palabra no nos pertenece, porque no se encuentra con facilidad, porque yace irremediablemente perdida. Como lo sabía el averroísmo, somos constitutivamente a-palabrados o, si se quiere, afásicos porque no hay continuidad entre vida y lógos pues, como indica Santa Cruz, no hay más que un "ángulo chueco que hay en el espacio" en el que salivamos palabras que, si bien podremos usar, jamás llegarán a ser nuestras. Cuando la palabra adviene como "nuestra" ella nos abandona en un naufragio insalvable.

Un pájaro que aún no vuela, un hombre que aún no piensa, el infans será un verdadero pingüino. Al no pensar (todavía), la narrativa del poder insiste en que el niño debe ser pensado. Al no pensar (todavía) el niño está excluido de la esfera pública, no tiene derecho a voto porque carece de palabra, no tiene derecho a decidir, porque está completamente privado de razón. El infans nada sabe, a diferencia del adulto que todo lo sabe y dispone. La fábula aún no ha tocado su cuerpo. No ha impreso su moral ni, por tanto, su lección. El "adulto" vuela con sus alas, el "niño" apenas balucea. Para la fábula, todos han de ser "adultos", esto es, seres eminentemente hablantes y morales, para Santa Cruz, todos somos infans abiertos a la errancia infinita de una boca que jamás encuentra su palabra.

Porque todos somos infans la palabra a nadie pertenece, porque estamos capturados por la fábula, la palabra es de exclusiva propiedad de algunos. Podemos ahora ofrecer una definición preliminar de la fábula: llamamos fábula a la reprogramación de la tecnología gubernamental en una dimensión neoliberal, la cual, tendrá tres efectos clave: en primer lugar, hacer del término "transición" no sólo un término digno de la teoría política, sino el término central de las nuevas formas de gobierno (Follegati 2018); en segundo lugar, la destrucción de las formas institucionales de la democracia (la república, expresada en la Constitución de 1925) por las nuevas técnicas de gobernanza operadas desde las formas del goverment by consent en las que la lógica de la confrontación se sustituye por la de la administración; en tercer lugar, destrucción de la democracia por la democracia, de la democracia de viejo cuño, con su pacto oligárquico de carácter estatal-nacional, por la democracia de nuevo cuño, con su nuevo pacto oligárquico de tipo corporativo-financiero.

"Transición" será la nueva raison d’etat de la gobernanza neoliberal contemporánea que sólo pudo funcionar si articulaba una narrativa estructurada como fábula. Y podemos, a su vez, denominar "transitología" a ese conjunto de reflexiones, discursos, teorías, y prácticas articulados desde fines de los años $70 \mathrm{y}$ durante todos los años 80 dedicados a regular un país desde el término político de 
"transición". Operando como dispositivo, la "transición" fue una raison d etat pues pudo suturar la relación entre palabra y cosa, entre lenguaje y cuerpos produciendo no sólo las fronteras de un orden político, sino sobre todo, una forma de subjetividad.

Desde el año 2006, los pingüinos comenzaron a destituir la seriedad "adulta" y mostraron que el lógos no era privativo de un grupo de expertos, sino una potencia común y totalmente impersonal. Mostraron que nada podía ser más desgarrador para los destinos de la ciudad, que los pingüinos volando, que los niños hablando. Si la razón transitológica relegaba el destino del país a un grupo de expertos articulados en la ficción del consenso, los pingüinos ingresaron a la ciudad, pusieron en circulación la palabra y mostraron que ésta se juega como una potencia común que no pertenece a nadie, ni siquiera a los "expertos" que "diseñaron" la transición como fábula: "Esta época escasa en que vivimos -escribía Santa Cruz en otro lugar-fue preparada con larga violencia; lo fue también por los técnicos del lenguaje" (2013 35). Técnicos que pretendieron la captura total del lenguaje "diseñando" a la fábula como una verdadera sutura de la infancia.

No se trata de que los "adultos" posean el lógos y los "niños" no; se trata de que lógos designa una potencia común que tensa la antropología articulada por la fábula mostrando que, independiente de las edades, jerarquías o divisiones sociales, todos los vivientes humanos somos constitutivamente infantes porque todos yacemos abismados cada vez, frente a nuestras propia capacidad o no de uso de la potencia de la lengua. Como bien, nos muestra Santa Cruz, esto significa que todos somos afásicos, o, lo que es igual, nuestra a-palabreridad que nos hace enteramente balbuceantes, nos hace devenir hablantes para restituir la radicalidad de nuestra afasia, nos dejamos atravesar por la intensidad de la palabra para que ésta huya de cuerpo en cuerpo, como un ave lo hace de árbol en árbol.

Ninguno puede definirse como propietario del saber o del pensar, porque ninguno puede apropiarse de la potencia común del lenguaje. Los pinguinos ingresan a la ciudad mostrando que todos los adultos que creían tener el acceso garantizado a la palabra, en rigor, eran tan afásicos como ellos. El trono está vacío, la palabra no es de nadie, ni tampoco de los adultos. Así, la destitución de la fábula es, sobre todo, destitución de una antropología que concibe al hombre como propietario del intelecto (un animal racional) y que sirve de soporte a la raison detat que definió a la "transición".

No habrá más hombres que saben y hombres que no saben, adultos e infantes. En ese instante, el simulacro de la fábula encuentra su implosión: cae, como se estrella un avión, se desploma como lluvia sobre los pueblos. Perece la ilusión de que "alguien" era dueño y señor de la palabra, de que "alguien" sabía como conducir a su rebaño. Nadie es dueño de la palabra y, por tanto, nadie sabe que hacer, nadie sabe cómo gobernar. El pastorado ha implosionado y ha comenzado a 
exhibir los colmillos del lobo feroz. El pastorado se ha perdido en la infancia del pueblo, en la intensidad de una potencia popular que abrió el carácter inapropiable de la palabra y su carácter irrevocablemente común. El pastor, la oveja y el lobo seguramente habrían vivido felices para siempre, pero no contaron con la mutación de la oveja en pingüino y su estallido en la potencia popular que, como diría Patricio Marchant, no podrá acontecer sino como un comentario acerca de la catástrofe.

\section{Bibliografía.}

Agamben, Giorgio. L'uso dei corpi. Vicenza: Neri Pozza, 2014.

Agamben, Giorgio. Infancia e historia. Destrucción de la experiencia y origen de la historia. Buenos Aires: Adriana Hidalgo, 2003.

Benjamin, Walter. "Para una crítica de la violencia". Letal e incruenta. Carlos Pérez López, Federico Rodríguez, Pablo Oyarzún, editores. Santiago: Lom, 2017.

Brenet, Jean Baptiste. Averroès l’inquiètant Paris: Les Belles Letres, 2015.

Brown, Wendy. El pueblo sin atributos. La secreta revolución del neoliberalismo. México: Malpaso, 2017.

Casanova, Carlos. Estética y Producción en Karl Marx. Santiago: Metales Pesados, 2016

Cavalletti, Andrea. Clase. El despertar de la multitud. Buenos Aires: Adriana Hidalgo, 2013.

Coccia, Emanuelle. La transparenza delle imagini. Averroè e l'averroísmo, Milano: Bruno Mondadori, 2005.

Derrida, Jaques. Seminario. La bestia y el soberano. Vol 1. (2001-2002). Buenos Aires: Manantial, 2010.

Foucault, Michel. El coraje de la verdad. Curso en el Collège de France 1984. Buenos Aires: FCE, 2010.

Follegati, Luna. La transición a la democracia. Genealogía de un concepto. Santiago: Universidad de Chile, 2018.

Kojéve, Alexandre. Introducción a la lectura de Hegel. Madrid: Trotta. 2014. 
Karmy, Rodrigo. "El milagro". El ABC del neoliberalismo. Mary Luz Estupiñan, editora.Viña del Mar: Communes, 2017.

Moulián, Tomás. Chile actual. Anatomía de un mito. Santiago: LOM, 1998.

Rancière, Jaques. El maestro ignorante. Cinco lecciones sobre emancipación intelectual. Santiago: Hueders, 2014.

Santa Cruz, Guadalupe. Ojo Líquido. Santiago: Palinodia, 2011.

Santa Cruz, Guadalupe. Lo que vibra por las superficies. Santiago: Sangría, 2013.

Uribe, Armando. El fantasma de la sin razón y El secreto de la poesía. Santiago: Be-UveDrais, 2001. 